\title{
Nutritional status of Romanian population and interventional programs to prevent obesity
}

\author{
Mirela Nedelescu ${ }^{*}$, \\ Alexandra Cucu ${ }^{1,2}$, \\ Andra Neamtu ${ }^{1}$ \\ Corina Zugravu ${ }^{1,2}$ \\ Lăcrămioara Brânduşe \\ ${ }^{1}$ National Institute of Public Health Romania \\ Dr. A. Leonte Street, no. \\ ${ }^{1-3}$ Bucharest, Romania \\ "Carol Davila" University of Medicine and \\ Pharmacy Bucharest, Romania \\ Received: $5^{\text {th }}$ October 2016 \\ Corresponding author: \\ MirelaNedelescu, \\ National Institute of Public Health, \\ Dr. Leonte Street, no. 1-3, Bucharest, Romania. \\ E-mail: mirela.nedelescu@insp.gov.ro
}

\begin{abstract}
Our work present data on the nutritional status of adult population of Romania in 2015 and the results of the school-aged children surveillance through the national surveillance program 2015 and also from two international programs - The European Childhood Obesity Surveillance Initiative (COSI), the national report 2013 and the Health Behaviour in School-aged Children Program (HBSC) from 2014.

The assessment of the nutritional aspects and health of adult population in relation to food consumption investigate the eating behaviours through consumption rates of nutrients and the main food groups, as well as anthropometric indicators of subjects included in the study. The data for 2015 show a decreased energy intake through food consumption, insufficient intake of dietary fiber and minerals (calcium, magnesium and selenium) and a high intake of proteins and total fats, especially saturated fats and cholesterol. The salt intake was situated above the WHO and European Commission's recommendations: more than $5 \mathrm{~g} /$ day - added salt and a total consumption of $10 \mathrm{~g}$ salt / day. These dietary mistakes are reflected in the increased percentage of the overweight subjects (43,1\% men, 36,2\% women respectively) and obese (30\% men and $27,2 \%$ women).

The COSI survey included 8-year-olds children from both rural and urban regions of Romania and the findings are as follows: $26,75 \%$ of the children included in the study are overweight or obese; the prevalence of childhood obesity is $11,64 \%$, with a higher rate of obesity in urban areas. The results of the HBSC study in 2014 indicate that a percentage of $26,6 \%$ of boys and $11,8 \%$ of girls aged 11,13 and 15 years old are overweight and / or obese.

These facts are the basis of the national interventional programs concerning the promotion of a healthy nutrition and lifestyle among population in order to reduce obesity and morbidity through cardiovascular diseases.
\end{abstract}

Keywords: Adult population, Children, Nutrition, Obesity, Overweight, Romania

\section{INTRODUCTION}

Overweight, obesity and diet-related diseases have reached epidemic proportions in recent years and are among the leading causes of mortality and morbidity in Europe and worldwide $[1,2,3]$ The unbalanced diet leads to an increasing number of people suffering from cardiovascular diseases (hypertension, myocardial infarction and atherosclerosis). The probability of meeting the global obesity target for 2025 is very low, and if these trends continue, the global obesity prevalence may reach in $202518 \%$ in men and $21 \%$ in women and the severe obesity will surpass $6 \%$ in men and $9 \%$ in women $[4,5]$.

In this context, Romania is facing the same challenges. Being a large country with approximatively 20 million inhabitants, $50 \%$ of them living in rural areas, Romania has an important share of population in poverty. According to ECHI Report 2012, 43\% of Romanian population is under the poverty line and the health expenditure per capita is the lowest among EU Member States [6]. The mortality through non-communicable diseases is estimated to account $92 \%$ of total deaths [7]. Risk factors for premature mortality due to noncommunicable diseases are tobacco smoking, alcohol consumption, raised blood pressure and obesity. The rate of obesity in 2008 was $19,1 \%$ ofthe total Romanian population, $16,9 \%$ for males and $21,2 \%$ for females [8]. This is associated with a low consumption of fruits and vegetables. Adults consumption profile indicate a consumption of $7,8 \mathrm{~kg}$ of bread / month / household (approximatively $160 \mathrm{gr} /$ day/person), $3 \mathrm{~kg}$ of meat / month / household, $0,845 \mathrm{~kg}$ of cheese / month / household, 2,6 kg of fruits / month / household and 5,4 kg of vegetables / month / household [9].

These data require the need to strengthen andimprove thenational policies and measures for the promotion of a healthy nutrition and lifestyle among population in order to reduce obesity and morbidity through non-communicable diseases. 


\section{MATERIALS AND METHODS}

Thispaper present data on the nutritional status of adult population of Romania in 2015 and the results of the school-aged children surveillance through the national surveillance program 2014/2015 and also from two international programs - The European Childhood Obesity Surveillance Initiative (COSI), the national report 2013 and the Health Behaviour in School-aged Children Program (HBSC) from 2014.

The assessment of the nutritional aspects and health of adult population in relation to food consumption is made within the national program of the Ministry of Health and investigate the eating behaviours through consumption rates of nutrients and the main food groups, as well as anthropometric indicators of subjects included in the study.

The assessment ofphysical development of children and youth in schools- both urban and rural communities, is made annually within the national surveillance program that includes preschool and school children aged 5 to 15 years. The prophylactic medical examination of health status of preschool and school childrenis a valuable tool for assessing the state of health at individual and population level, being one of the most important methods utilized in public health and preventive medicine. Within the national surveillance program for the school year 2014/2015, were examined a number of 641650 preschool and school children.

The nutritional status assessment of children from elementary schoolswas made at national level by participating in the "European Childhood Obesity Surveillance Initiative (COSI).The COSI survey included 8-year-olds children from both rural and urban regions of Romania.

The Health Behaviour in School-aged Children study (HBSC) -2014 , under the auspices of the World Health Organization Regional Office for Europe (WHO) included the assessment of the nutritional status through BMI, eating habits (consumption of fruits and vegetables, sweets and carbonated drinks), the level and time of physical activity, the substance use (smoking and alcohol) and sexual behaviour among children of 11,13 , and 15 year olds.

For all subject included in above mentioned studies were made measurement of weight and height, samples of subjects included in studies being representatives at the national level. Food frequency questionnaires were applied in order to assess the consumption of different food categories.

\section{RESULTS AND DISCUSSIONS}

Eurostat data show that the overall trend in Europe is the growing number ofobesity cases with advancing age. In Romania, the European Commissiondata show that the highest percentage of obese people was registered for the age group $45-64$ years $(13,7 \%$ in women and $10,7 \%$ in men), identifying a slight decrease (from 10,8\% in women and $10,5 \%$ in men) in population over 65 years [7].

A total of 1705 adult subjects were included in the nationally representative sample for the assessment of nutritional status of adult population in Romania in 2015, of which 1044 were women $(62,2 \%)$ and 661 men $(38,8 \%)$. The average age of subjects included in study was $51,7 \pm 15,4$ years. As regard the residence area, 768 subjects were in urban areas (45\% of the total population) and 937 were from rural areas (55\% of the total population).

Body mass index (BMI) calculation revealed an increased proportion of overweight and obese subjects. It has registered a rate of $43,1 \%$ overweight and $30 \%$ obese in men. Also, 36,2\% of women included in studywere overweight and $27,2 \%$ were obese (Figure 1 ).

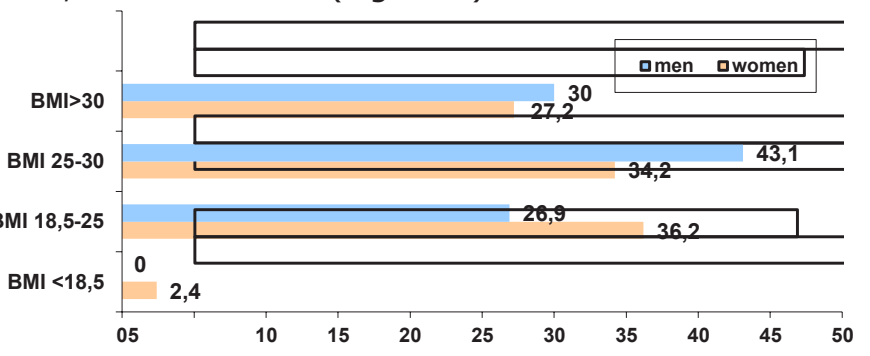

Figure 1. Distribution of adult population by BMI and gender (percentage values indicated)

The data collected by applying food frequency questionnaires in the studied population show a decreased energy intake through food consumption, insufficient intake of dietary fiber and minerals (calcium,magnesium and selenium) and a high intake of proteins and total fats, especially saturated fats and cholesterol (Table 1 and Table 2). The salt intake was situated above the WHO and European Commission's recommendations: more than $5 \mathrm{~g} /$ day - added salt and a total consumption of $10 \mathrm{~g}$ salt / day.

Table 1. Daily intake of macronutrients by study population and dietary recommendations

\begin{tabular}{|l|c|c|c|c|c|c|}
\hline \multirow{2}{*}{ Study population } & \multicolumn{5}{|c|}{ Daily intake of nutrients by study population } \\
\cline { 2 - 7 } & $\begin{array}{c}\text { Proteins } \\
\text { (g/day) }\end{array}$ & $\begin{array}{c}\text { Carbohydrates } \\
(\mathrm{g} / \text { day })\end{array}$ & $\begin{array}{c}\text { Dietary fiber } \\
(\mathrm{g} / \text { day })\end{array}$ & $\begin{array}{c}\text { Total fats } \\
(\mathrm{g} / \text { day })\end{array}$ & $\begin{array}{c}\text { Saturated fat } \\
(\mathrm{g} / \text { day })\end{array}$ & $\begin{array}{c}\text { Cholesterol (mg/ } \\
\text { day })\end{array}$ \\
\hline Men & 125 & 286,6 & 11 & 126,3 & 44 & 658 \\
\hline Women & 114,5 & 267,2 & 11 & 108 & 36,9 & 586 \\
\hline $\begin{array}{l}\text { Average energy intake } \\
\text { covered by nutrients } \\
\text { daily }\end{array}$ & $\begin{array}{c}18- \\
18,7 \%\end{array}$ & $\begin{array}{c}40,3 \%- \\
43,3 \%\end{array}$ & - & $\begin{array}{c}39,4 \%- \\
41 \%\end{array}$ & - & - \\
\hline Recommendations* & $15 \%$ & $55 \%$ & $25-35$ & $15-30 \%$ & 30 & 300 \\
\hline
\end{tabular}

*according to Romanian Ministry of Health and Romanian Society of Nutrition [13] 
The nutritional status of children is annually investigated within the national surveillance program.From the total of 641650 preschool and school children examined in the school year $2014 / 2015,74,3 \%$ of them (476489 children) presented an harmonic physical development and $25,7 \%$ (165161 children) a disharmonic physical development (underweight and overweight or obese).

In urban areas overweight and obese children represent $15,7 \%$ of total subjects, while in rural regions they account $9,2 \%$ of total subjects having residency in these areas. In rural areas the percentage of children with disharmonic physical development is lower than in urban areas $(17,9 \%$ vs. $27,5 \%$ ). In urban regions the percentage of children with harmonic development is lower by over $9 \%$ compared to rural areas (Figure 2 ).

Figure 2. Distribution of children by physical development status and residence

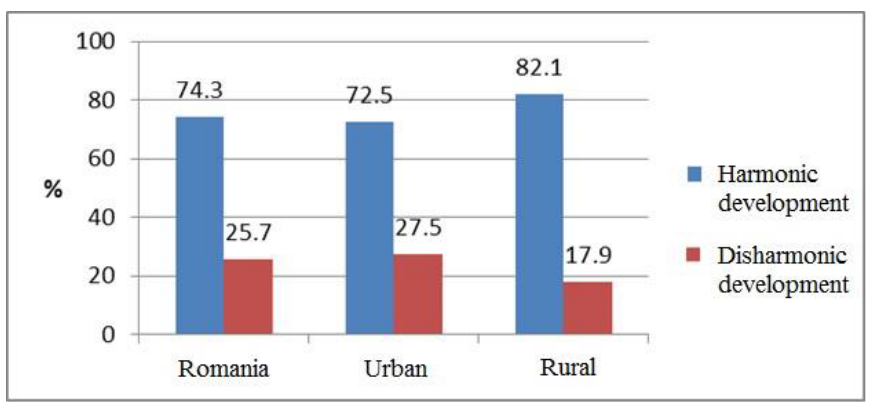

The findings of COSI survey are: $26,75 \%$ of the8-year-olds children included in the study are overweight or obese; the prevalence of childhood obesity is $11,64 \%$, with a higher rate of obesity in urban areas. Thus, the majority of children included in the study were normal weight $(68,15 \%)$. The distribution of subjects by gender and nutritional status is presented in Figure 3.

Underweight (BMI $<18,5$ ) was present at 5,11 $\%$ of children included in survey, $1,22 \%$ of children presenting a severe underweight $($ BMI $<16)$.

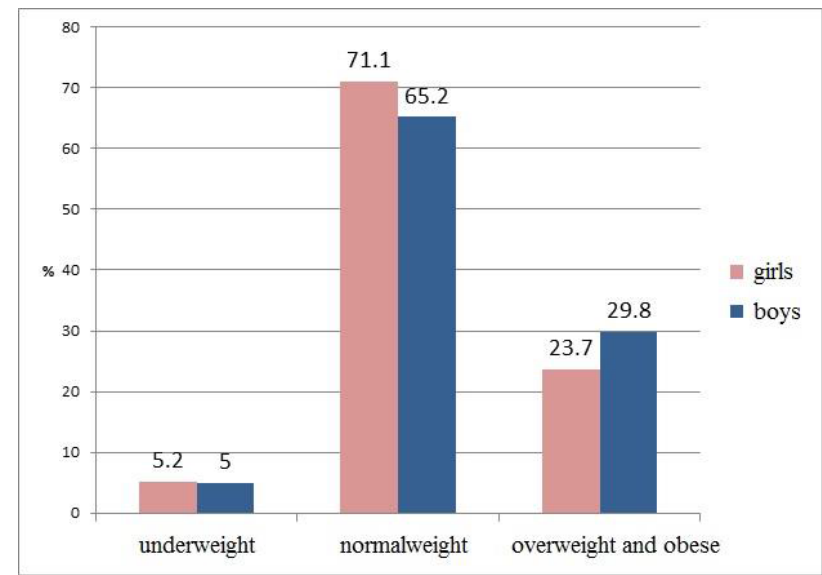

Figure 3. Distribution of the Romania COSI study subjects according to the nutritional status and gender

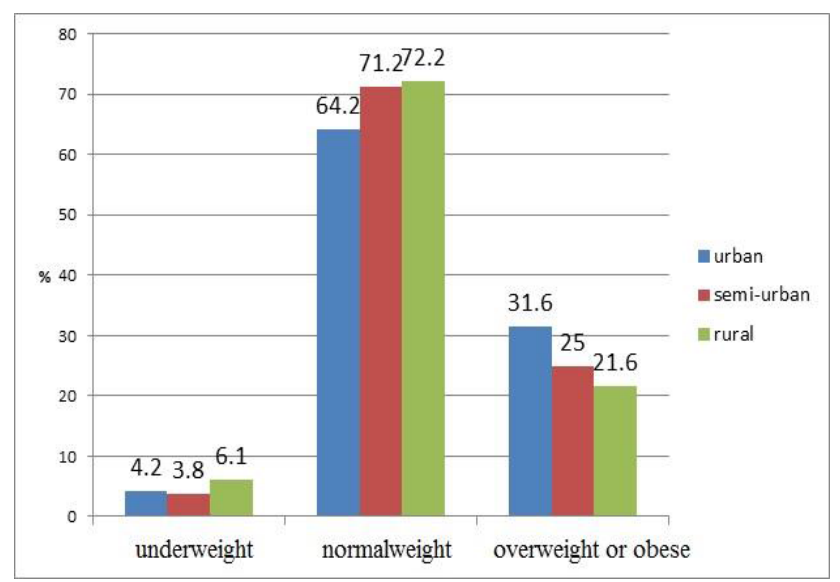

Figure 4. Distribution of the Romania COSI study subjects according to the nutritional status and residence

The prevalence of childhood overweight and obesity is $31,6 \%$ in urban areas and $21,7 \%$ in rural areas. A quarter of children living in semiurban regions are overweight or obese (Figure 4). The highest prevalence of obesity in childrenof 8 years old in Romania was registered in urban areas

Table 2. Daily intake of micronutrients by study population and dietary recommendations

\begin{tabular}{|c|c|c|c|}
\hline \multirow[t]{2}{*}{ Study population } & \multicolumn{3}{|c|}{$\begin{array}{c}\text { Daily intake of nutrients by study } \\
\text { population }\end{array}$} \\
\hline & $\begin{array}{l}\text { Calcium } \\
\text { (mg/day) }\end{array}$ & $\begin{array}{c}\text { Magnesium } \\
\text { (mg/day) }\end{array}$ & $\begin{array}{l}\text { Selenium } \\
(\mu \mathrm{g} / \text { day })\end{array}$ \\
\hline Men & 770 & 329 & 68,7 \\
\hline Women & 698 & 284 & 58,8 \\
\hline Recommendations* & 1200 & 400 & 70 \\
\hline
\end{tabular}

*according to Romanian Ministry of Health and Romanian Society of Nutrition [13] 
$(13,15 \%)$, followed by rural areas $(10,18 \%)$ and semi-urban areas $(9,85 \%)$.

According to thefirst round of COSI report, the prevalence of overweight (including obesity) in thechildrengroup aged 8 years ranged between $22,1 \%$ (Belgium) and $49 \%$ (Italy) for boys and between 22,7\% (Belgium) and 42,5\% (Italy) for girls. Obesity prevalence ranged between $7,5 \%$ (Norway) - 26,6\% (Italy) in boys and between $6 \%$ (Norway) - Italy $17,3 \%$ in girls [10].

The results of the HBSC study in Romania in 2014 indicate that a percentage of $26,6 \%$ of boys and $11,8 \%$ of girls aged 11,13 and 15 years old are overweight and / or obese.Almost a third of boys and $12 \%$ of girls aged 11,13 and 15 are overweight and / or obese.The rate of overweight and obesity among boys is almost double that the rate of girls. The prevalence of overweight and obesity gradually decreases from the age 11 to 13 and to 15 years. There is an increasing trend for the prevalence of overweight / obesity in adolescents aged 11, 13, 15 years in the period 2006-2010-2014, more evident in boys.

We noticed a slightly increase ofoverweight and obese boys from 2006 to 2014. It can be observed a low increase of the percentage of overweight or obesityamong girls, between 2006 and 2010, and a low decrease for 2014 (Figure 5).

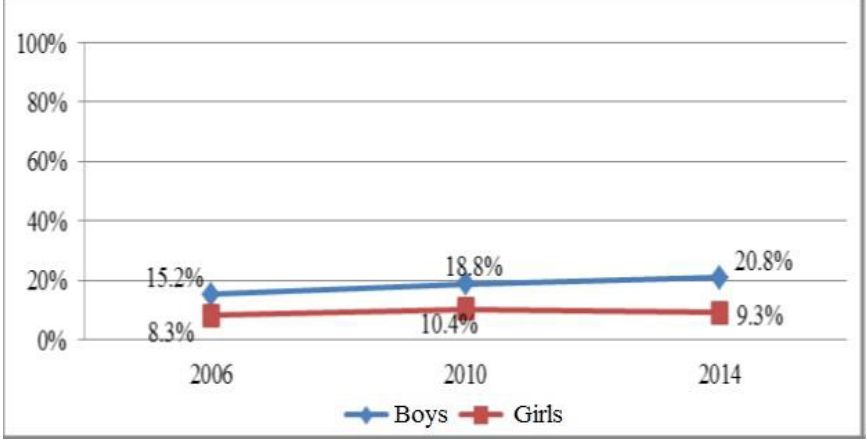

Figure 5.The prevalence of overweight and obese children - HBSC Romania survey

HBSC survey investigated also the consumption of fruits andvegetables among children. The results are as follows: only $34 \%$ of boys and $41 \%$ of girls consumed fruits daily. The percentage of children consuming fruits daily decreases significantly with age, only $25 \%$ of 15 years old boys and $34 \%$ of 15 years old girls keeps this healthy food habit.Daily consumption of fruits among children aged 11, 13,15 years declined steadily in the period 20062010-2014. There is also a constantly decreaseof vegetable consumption from 11 to 13 years old children and from 13 to 15 years.

Despite it was observed a low increase of daily fruit and vegetable consumption in the period 20062010-2014, this food habit is currently present in a relatively small percentage of children.

\section{National interventional programs prevent obesity}

to

The results of above mentioned studies outline the need of consistent national interventional programs concerning the promotion of a healthy nutrition and lifestyle among population in order to reduce obesity and morbidity through noncommunicable diseases.

Romania policies and measures on nutrition include national health programs and integrated plansfor health promotion and health education. Thenormative acts such as Law no. 123/2008 for healthy nutrition in schools [11] and the Ministry of Health Order no. 1563/2008 on approval of the list of not recommended food for children [12] set up the Ministry of Health recommendations on children nutrition and the foods that are banned to be sold in schools: all food containing more than $1,5 \mathrm{~g}$ salt/ $100 \mathrm{~g}$ product or more than $0,6 \mathrm{~g} \mathrm{Na} / 100$ $\mathrm{g}$ product; foods high in fat (over $20 \mathrm{~g}$ of fat/ 100 $\mathrm{g}$ product, of which maximum $5 \mathrm{~g}$ saturated fat / $100 \mathrm{~g}$ product and maximum $1 \mathrm{~g}$ trans fatty acids / $100 \mathrm{~g}$ product); foods high in sugars (more than $15 \mathrm{~g}$ sugars / $100 \mathrm{~g}$ product) and high energy foods (over 300 calories per unit of sale). Ministry of Health and Romanian Society of Nutrition elaborated in 2006 the Guidance for healthy eating that contains the nutritional recommendations of health professionals for all age groups [13].

National health promotion activities include annually information activities occasioned by the World Heart Day, Obesity Day, Hypertension Day, European Obesity Day and other events promoting a healthy life and organized at national level.

Also, the national project"Multilevel interventions for the prevention of the noncommunicable diseases associated with lifestyle in Romania" [14], co-financed by Norway grants and Ministry of Health Romania, developed activities aimed to increase the capacity of educational and professional institutions (schools and kindergartens) in pilot communities, in collaboration with health professionals. The project was carried out in the period 2014-2016 and the scope of theproject was to promote and reinforce healthy behaviors, including healthy nutrition and healthy lifestyle at an early age.

\section{CONCLUSIONS}

The dietary mistakes of Romanian adult population (high intake of proteins and total fats, especially saturated fats and cholesterol) are reflected in the increased percentage of the overweight adult subjects (43,1\% men, 36,2\% women respectively) and obese (30\% men and $27,2 \%$ women).

The assessment of children nutritional status indicate that a percentage of $26,75 \%$ of 8 years old children are overweight or obese (COSI survey) and a percentage of $26,6 \%$ of boys and $11,8 \%$ of girls aged 11,13 and 15 years old are overweight and / or obese (HBSC, 2014). The majority of children included in these studies are normal weight, regardless of their gender or their residence.

Therefore, these studies reinforce the challenge for a better implementation of public health policies in order to prevent childhood and adult obesity and to reduce the morbidity through non-communicable diseases. 


\section{REFERENCES}

1. R C Davey. The obesity epidemic: too much food for thought?Br J Sports Med 2004; 38:360-363.

2. WHO. Obesity and overweight. Fact sheet No. 311. World Health Organization, Geneva, 2015.

3. Lim SS, Allan K, Bhutta ZA et al. GBD 2015 SDG Collaborators. Measuring the healthrelated Sustainable Development Goals in 188 countries: a baseline analysis from the Global Burden of Disease Study 2015. Lancet 2016.

4. NCD Risk Factor Collaboration (NCD-RisC). Trends in adult body-mass index in 200 countries from 1975 to 2014: a pooled analysis of 1698 population-based measurement studies with $19 \cdot 2$ million participants. Lancet. 2016; 387: 1377-1396.

5. WHO. Comprehensive implementation plan on maternal, infant and young child nutrition 2012-2025. World Health Organization, Geneva, 2014.

6. National Institute of Public Health Romania. The health profile based on ECHI indicators Romania 2011. Bucharest, 2012: 14-15.

7. European Commission Health Data. Eurostat Statistics Database,2012.Available from: http://ec.europa.eu/eurostat/data/ database

8. WHO. Non-communicable diseases country profiles, 2014. Available from: http://www. who.int/nmh/publications/ncd-profiles-2014/ en/

9. National Institute of Statistics. Household budget survey Report, 2012.Available from: http://www.insse.ro

10. WijnhovenTMA etal.WHO European Childhood Obesity Surveillance Initiative: body mass index and level of overweight among 6-9-yearold children from school year 2007/2008 to school year 2009/2010. BMC Public Health 2014; 14:806-21.

11. Ministry of Health Order no. 1563/2008 on approval of the list of not recommended food for children. Available from: http://www. ms.ro(in Romanian)

12. Law no. $123 / 2008$ for healthy nutrition in schools. Available from: http://www.ms.ro(in Romanian)

13. Romanian Society of Nutrition. Guidance for healthy eating. Iasi, 2006. Available from: http://www.ms.ro/documente/ Ghid1 8318 6022.pdf (in Romanian)

14. National Institute of Public Health Romania. Project "Multilevel interventions for the prevention of the non-communicable diseases associated with lifestyle in Romania". Available from: http://insp.gov.ro/sites/1/ 